\title{
Composition, group size, and spatial distribution of European bison bulls in Białowieża Forest
}

\author{
Małgorzata KRASIŃSKA and Zbigniew A. KRASIŃSKI
}

Krasińska M. and Krasiński Z. A. 1995. Composition, group size, and spatial distribution of European bison bulls in Białowieża Forest. Acta Theriologica 40: 1-21.

European bison Bison bonasus (Linnaeus, 1758) bulls were observed in the Białowieża Primeval Forest between 1976 and 1990. During snow-free periods mean $( \pm$ SD) group size was $1.63 \pm 1.05$. Mean group size in pre-rut was $1.83 \pm 1.19$ and was significantly $(p<0.001)$ larger than mean bull group size in rut $1.27 \pm 0.63$. Most often bulls were solitary $(62.0 \%)$, small groups of up to 3 bulls were accounted in $32.2 \%$ of observations, and groups of $4-9$ individuals in $5.8 \%$ of observations. In pre-rut period bulls active in reproduction (6-11 years old) secluded themselves from mixed groups; they lived solitary or in bull groups. Mean summer home range size of bulls over 4 yrs old was $2288.0 \pm 696$ ha. Mean monthly home range in pre-rut period was $963.3 \pm 406.4$ ha, i.e. significantly $(p<0.001)$ smaller than in rut $(1662.0 \pm 510.6$ ha). In the snow-free season bulls mostly used fresh and moist deciduous forests $(48.8 \%$ of encounters), and secondly mixed coniferous and mixed deciduous forests (28.9 and $19.1 \%$ ). Bulls used tree stands more than $20 \mathrm{yrs}$ old ( $54.3 \%$ of observations), but also open areas, i.e, young plantations up to 10 yrs of age, clearcuts and meadows (alltogether $37.3 \%$ of observations). In winter, on an average $35 \%$ of adult bulls entered large mixed aggregations gathering near two supplementary feeding sites. The remaining bulls took advantage of other feeding racks or enter farmland. Mean winter home range size of bulls was $426.1 \pm 307 \mathrm{ha}$, and is significantly positively correlated to the animal age.

Mammal Research Institute, Polish Academy of Sciences 17-230 Białowieża, Poland (MK); the Białowieża National Park, 17-230 Białowieża, Poland (ZAK)

Key words: Bison bonasus, bull group size, home range, habitat use, spatial distribution, Białowieża Primeval Forest, Poland

\section{Contents}

Introduction

Material and methods

Snow-free period

Winter period

Results

Social relations

Size and structure of bull groups during the snow-free season

Share of bulls in various groups in the snow-free season

Presence of bulls in winter aggregations

Stability of bull groups

Spatial distribution

Snow-free season

Winter season

Habitat use 
Discussion

Social relations of bulls $\quad 15$

$\begin{array}{lr}\text { Spatial distribution } & 17\end{array}$

Habitat use

References

\section{Introduction}

European bison Bison bonasus (Linnaeus, 1758) is a gregarious animal with the basic social units in the population being mixed and bull groups. The snow-free season, when bison have no supplemental feeding, provides an opportunity to form the herd structure of the bison population.

The Białowieża population of European bison has been studied since its creation in 1952-1960. The first 20 years of study provided data about the population's development (Krasiński 1967, 1983), some aspects of ecology (Krasiński 1978), reproduction (Krasiński and Raczyński 1967) and behavior (Caboń-Raczyńska et al. 1983, 1987). Animals were individually marked in 1978-1981 (Krasiński et al. 1982) thus enabling more detailed ecological research on herd distribution, movements, stability and habitat use. Some of the results regarding mixed groups were published earlier (Krasińska et al. 1987). In this paper we present data on the size and composition, the spatial distribution, and habitat use of bull groups. Preliminary results of habitat use by bulls were published previously (Krasińska and Krasiński 1991).

\section{Material and methods}

Studies were conducted between 1976 and 1990. During the snow-free period (May-October), which includes the growing season, observation were divided into pre-rut (May-July) and rut (August-October). For winter period studies were conducted between December and March.

Climatic data concerning the Bialowieża Forest and applied in this paper were gathered at the weather-station located in the middle of the Białowieża Glade. Winters were classified as mild (average daily temperature $>-1^{\circ} \mathrm{C}$ ), and severe (average daily temperature $<-1^{\circ} \mathrm{C}$ ).

\section{Snow-free period}

Observations in this period were carried out in the south-eastern Polish part of the Białowieża Forest, on a area of about 7000 ha (Fig. 1). A detailed description of this research area is included in an earlier paper by Krasińska et al. (1987).

The method of direct observation of bison was used. Any encounter with solitary bull or a bull group was counted as an observation. Subject to observations were both marked males and unmarked ones possessing individual traits. In 1978-1988, 32 bulls were marked with numbers frozen on their skins with liquid nitrogen (Krasinski et al. 1982). These marked bulls were monitored during periods of 1-10 years, yet only four individuals out of this number through some years: No 19 for $10 \mathrm{yrs}$, No $5-9 \mathrm{yrs}$, No $25-8 \mathrm{yrs}$, and No $16-7 \mathrm{yrs}$. Some of the marked bulls had to be eliminated, others vanished or died in the subsequent years of study. In particular years $6-16$ animals were monitored simultaneously. The maximum number of marked males, i.e. 16, was noted in 1985.

In the snow-free period investigations concerned the size and composition of bull groups, the participation of bulls in mixed groups and bulls group, habitat use and home range size. Approximate 


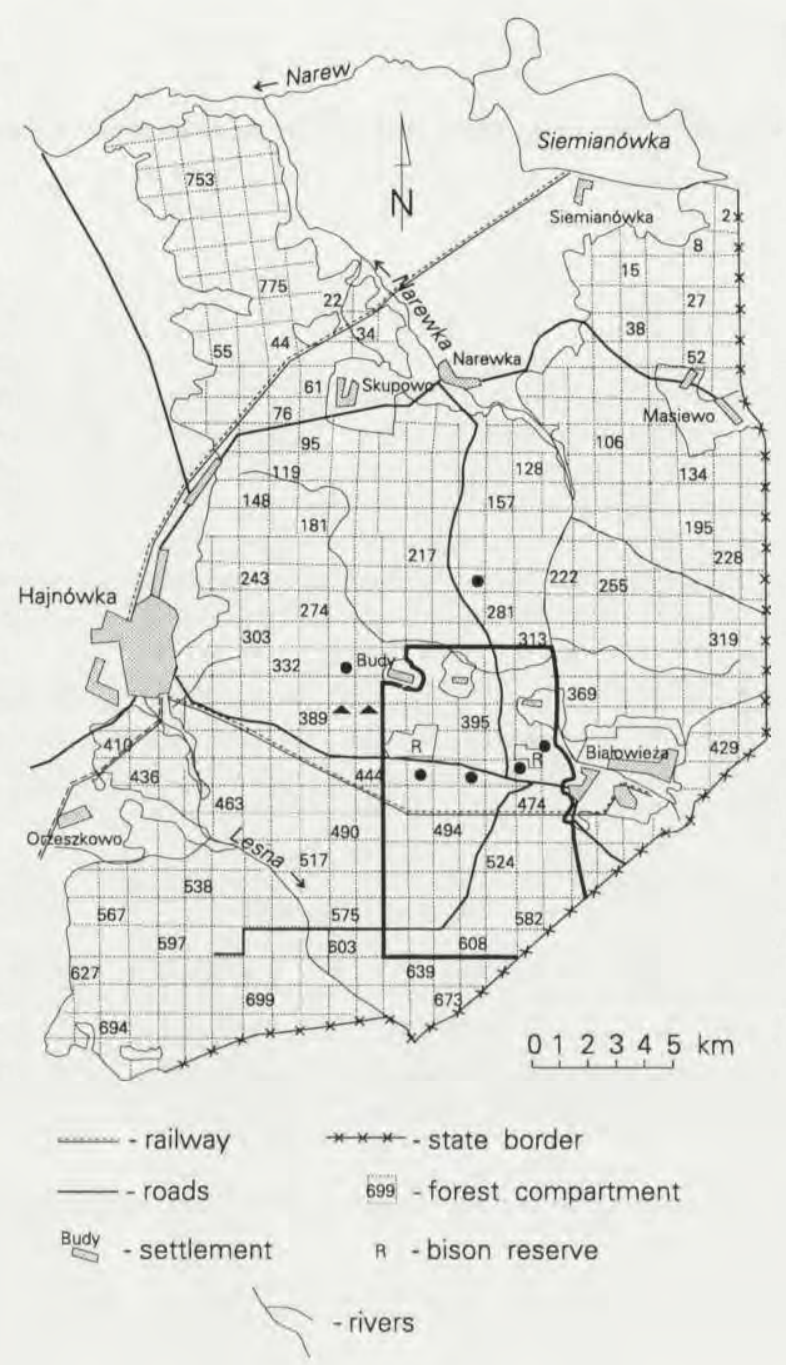

Fig. 1. Observation area of European bison bulls in the Białowieża Primeval Forest for 1976-1990 during snow-free period and supplementary feeding sites during winter. The study area is delimited by the thick line. Triangles denote the feeding sites of mixed aggregations in winter in forest compartments Nos 390-391 and 422. Closed circles denote supplemental feeding sites for bulls.

ages of the unmarked males were estimated. Each time the place of encounter (the number of a forest compartment) and form of activity (e.g. feeding, resting, roaming) were registered. While investigating the habitat use of bulls, both solitary ones and members of bull groups, the forest type and timber stand ages were determined.

Observations were carried out every day, usually early in the morning, but also in the afternoon or evening. Data were drawn into observational charts. Encounters with bulls were marked on a map of the forest provided with a net of square compartments. The length of a compartment side was $1066 \mathrm{~m}$ (one verst). Home ranges size of bulls were determined using the minimum convex polygon method through daily direct localization of marked males under $4 \mathrm{yrs}$ of age roaming solitary or in groups; if 
this was impossible, then by following tracks. In this way the monthly home range of one individual or a bull group was found. The findings were exact to 1 forest compartment (acreage of $111 \mathrm{ha}$ ). Consequently, 37 monthly home ranges for 11 marked bulls were determined.

Summer home range sizes of bulls (May-October) were established by locating the same marked, adult bull at least 10 times in each of the subsequent months of the given summer season. Summer home range sizes are accurate to one forest compartment. Consequently, 34 summer home ranges for 20 marked bulls were calculated for various years of study.

\section{Winter period}

During winter investigations were carried out over the entire Białowieża Forest and its peripheries. Observations were made biweekly by checking all supplemental feeding sites (Fig. 1). Bulls found either as solitary or in groups were recorded. Once a week the forest was penetrated by car to note all encounters with bulls. Twice per each winter month the farmland surrounding the forest was penetrated by car, and locations of encounters with bulls or their tracks were registered.

The winter home range, like the summer one, was determined through biweekly locations. Consequently, 87 winter home ranges of 27 marked bulls during 13 years were calculated. For determining the spatial distribution of bulls in winter additional observations from forestry workers both in and off the forest were used.

We tested for significant differences in group sizes and home range sizes by using the Mann Whitneys $U$-test. The relation between bull ages and the sizes of their home ranges, and the size of groups were studied with the use of simple linear regression.

\section{Results}

\section{Social relations}

Size and structure of bull groups during the snow-free season

Mean bull groups size in snow-free period was $1.63 \pm 1.05(n=924$ observations of groups); the number of males observed varied from 1 to 9 . Mean $( \pm$ SD) size in

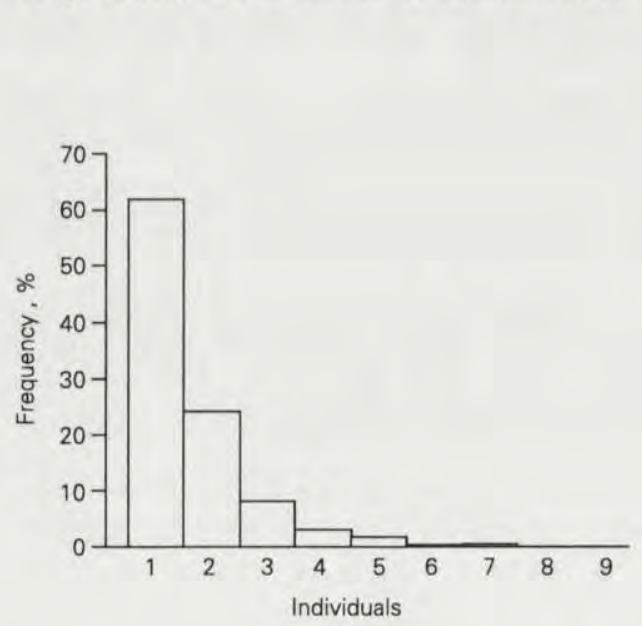

Fig. 2. Percent frequency of occurrence of bulls in different group sizes during snow-free period. Total number of observations $n=924$.

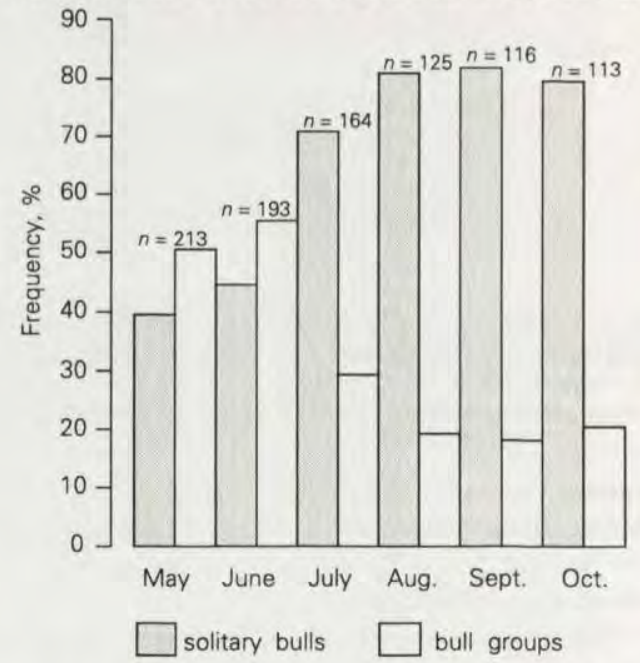

Fig. 3. Seasonal changes in $\%$ frequency of occurrence of bulls either solitary or in groups during the snow-free period. $n=924$ observations. 
pre-rut was $1.83 \pm 1.9$ and was significantly $(p<0.001)$ larger than mean bull groups size in rut $(1.27 \pm 0.63)$. Most bulls were solitary $(62 \%)$, the remaining formed usually small groups of 2 or 3 individuals (Fig. 2). The number of solitary bulls depended on a season; it increased visibly at the end of July when the rutting period began and remained high (about 80\%) till the end of October (Fig. 3). Most solitary bulls were over 7 years of age ( $73.5 \%$ observations), $22 \%$ were $5-6 \mathrm{yrs}$ old. Younger bulls, $2-4$ yrs old, were rarely observed as solitary $(0.5 \%$ and $4 \%$ respectively). Bull group size was significantly negatively correlated with age $\left(n=645, r=-0.41, p<0.001, R^{2}=16.7\right)$.

Share of bulls in various groups in the snow-free season

One- and two-year-old males lived in mixed herds with females. Only occasionally they were observed in male groups. Bulls 3-5 yrs old lived most often in mixed groups, although they were also found in bull groups (Fig. 4). In the pre-rut

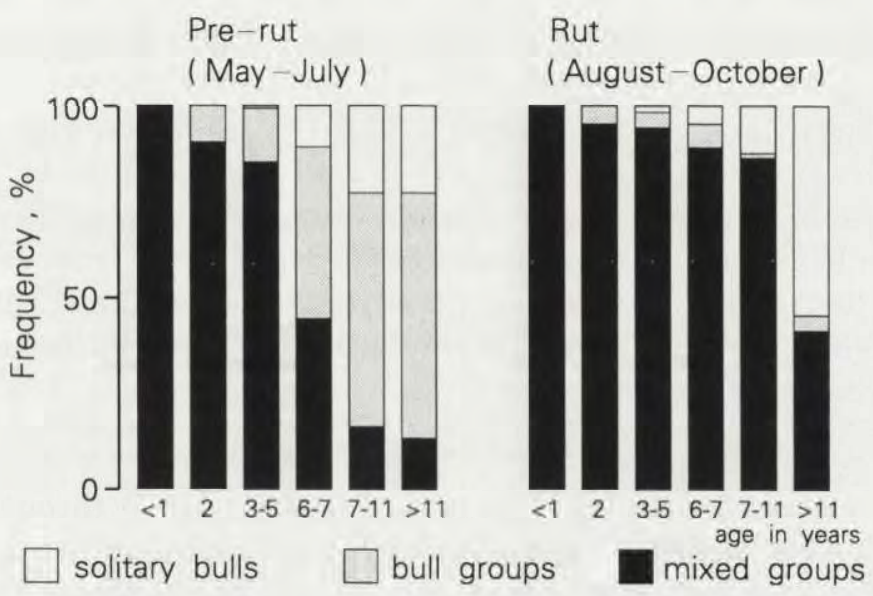

Fig. 4. Frequency of observations of marked bulls found in different types of groups in relation to their age during snow-free period. $n=2168$ observations.

period bulls $6-11$ yrs of age, capable of taking part in reproduction, were mostly absent from mixed herds and they formed bull groups or were solitary (Fig. 4). Older males (over 11), both before and during the rutting period, were more frequently observed alone or in bull groups than in mixed herds (Fig. 4).

\section{Presence of bulls in winter aggregations}

During winter young bulls $(<4$ yrs old) participated in large mixed aggregations. Occasionally, older males were also members of large aggregations, but these were very unstable. A mean of $35 \%$ of adult bulls were in mixed aggregations. The remaining $65 \%$ were bull only groups, suggesting the share of bulls in various types of aggregations during winter is age dependent. There was yearly variation 


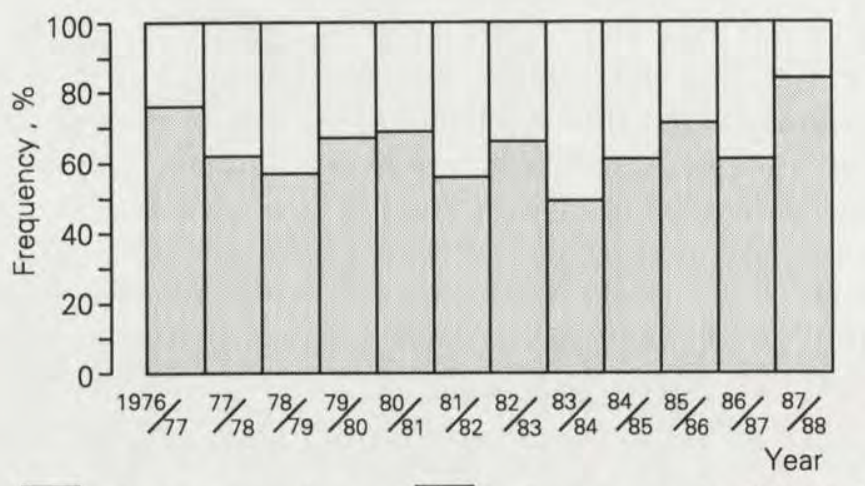

mixed aggregations $\square$ bull groups and solitary bulls

Fig. 5. Frequency of occurrence of bulls in winter aggregations of mixed groups or bulls only.

in number of bulls found in mixed aggregations: $16 \%$ (winter 1987/88) to $51 \%$ (winter 1983/84) (Fig. 5).

In winter, mean bull group size was $2.65 \pm 1.87$ (365 observations of groups). This is significantly larger $(p<0.001)$ than bull group size in both pre-rut and rut periods. Bulls staying close to feeding sites form aggregations of up to 9 individuals. Bulls found away from feeding sites in the forest were usually solitary. Both solitary males and bull groups $(\bar{x}=3.9 \pm 3.1$ individuals, range $1-12, n=$ 70 observations of groups, Krasiński, in litt.) went to the fields outside the Białowieża Primeval Forest.

\section{Stability of bull groups}

The composition and size of bull groups changes frequently throughout the year. The number of days spent by marked males in one bull group varied from 1 to 33 . During the snow-free season the figure was $7.6 \pm 7.7$ days (Table 1 ). The number of days spent by a male in one group was significantly correlated neither with a

Table 1. The stability of the bull group composition (1976-1990).

\begin{tabular}{|c|c|c|c|c|c|c|c|c|c|c|}
\hline \multirow{3}{*}{ Period } & \multicolumn{10}{|c|}{ Time of group stability (days) } \\
\hline & \multicolumn{5}{|c|}{ Bulls $3-5$ yrs old } & \multicolumn{5}{|c|}{ Bulls $>6$ yrs old } \\
\hline & $n$ & $\bar{x}$ & SD & Min & $\operatorname{Max}$ & $n$ & $\bar{x}$ & SD & Min & $\operatorname{Max}$ \\
\hline \multicolumn{11}{|l|}{ Snow-free period: } \\
\hline April & & & & & & 18 & 7.1 & 6.9 & 1 & 25 \\
\hline Pre-rut (May-July) & 6 & 10.3 & 7.1 & 4 & 22 & 68 & 7.7 & 7.7 & 1 & 33 \\
\hline Rut (August-October) & 2 & 6.0 & & 4 & 8 & 15 & 6.8 & 7.5 & 1 & 16 \\
\hline Total & 8 & 9.2 & 6.4 & 4 & 22 & 101 & 7.6 & 7.7 & 1 & 33 \\
\hline Winter (with snow cover) & & & & & & 26 & 9.4 & 7.8 & 2 & 25 \\
\hline
\end{tabular}


Table 2. The number of days spent by a marked bulls in a mixed groups during the rutting period.

\begin{tabular}{lccccc}
\hline Group of animals & $n$ & $\bar{x}$ & SD & Min & Max \\
\hline Bulls 3-5 yrs old & 28 & 8.2 & 7.1 & 2 & 6 \\
Bulls > 6 yrs old & 34 & 6.3 & 6.2 & 1 & 29 \\
\hline
\end{tabular}

bull's age nor with the season. A group of bulls remained in an unchanged composition for the shortest period of time during rutting but this time did not differ considerably from those of other seasons (Table 1). Bulls active in reproduction (over 6 yrs old) moved more often between mixed groups and they remained in one group for a shorter period of time ( $6.3 \pm 6.2$ days) than young bulls $(8.2 \pm 7.1)$, but this difference was not significant (Table 2). Marked males between 6 and $11 \mathrm{yrs}$ of age visited from 1 to 6 mixed groups during one rutting period ( $2.4 \pm 1.3$ groups). During winter the average stability of bull groups was $9.4 \pm 7.8$ days.

\section{Spatial distribution}

Snow-free season

The analysis of bull home ranges during that period was based on data on marked males $>4$ yrs old. These bulls roamed solitary or in small groups of up to 3 animals. Bulls between 4 and 11 yrs of age had a home ranges of 1332-3774 ha, mean $2288.0 \pm 696$ ha ( $n=34$ determined ranges). Older bulls, over 11 yrs old $(n=3)$, had significantly smaller $(0.05<p<0.02, n=20)$ home ranges of $1406 \pm 448.6$ ha.

Pre-rut monthly home range size varied from 222 to 1776 ha. This maximum size was observed only once, in June 1988. Mean monthly home range size was $963.2 \pm 406.4$ ha $(n=26)$. This was significantly $(p<0.001)$ smaller than during rut, mean $1662 \pm 510.6$ ha, $n=11$ (Figs 6 and 7 ). In the same periods of succeeding years the same bull covered different areas.

We possess few data concerning the size of monthly range areas of old bulls. These animals roam through small areas, both in the pre-rut period and rut, they are mobile to a small degree. For example, a 15-year-old bull, recognized thanks to some individual features, covered monthly home range areas of 222 and 333 ha in the pre-rut period, whereas 555 ha during the rut. The home ranges were not protected by males, so they partly overlaped (Figs 7 and 8).

\section{Winter season}

Each year only $1 / 3$ of adult bulls gathered together with the large mixed aggregations in forest compartments Nos 390-391 and 422 (Figs 1 and 9). The remaining bulls gathered around other feeding sites or did not approach these sites at all. Some moved towards farmland beyond the forest (Fig. 9). Males both the 3-4-year-old and older ones, roamed between the mixed aggregations throughout the whole winter. During the first 6 years of study the marked bulls coming 


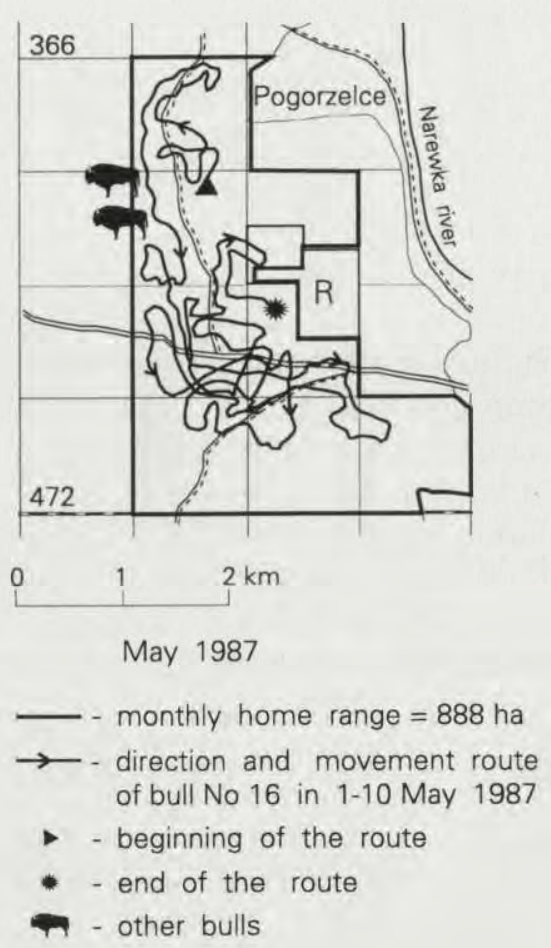

Fig. 6. Monthly home range and movement route of bull No 16 in pre-rut period. For explanation see Fig. 1

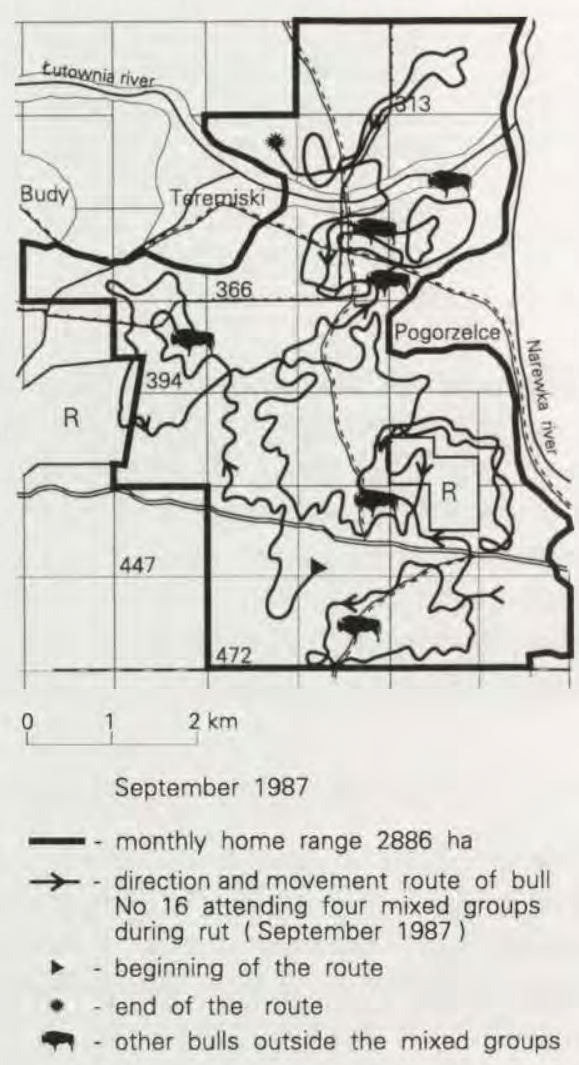

Fig. 7. Monthly home range and monthly route of bull No 16 in rut. For explanation see Figs 1 and 6 .

from mixed aggregation living in the compartment No 422 were monitored for long periods in the other mixed aggregation in the compartment 391 (10 different individuals in subsequent years; Krasińska et al. 1987). In the following years, however, they were no longer found there.

We determined winter home ranges for 27 marked bulls. All of the bulls were marked at feeding sites in the 422 and nearby forest compartments ( 446 and 448 ; Fig. 1). In subsequent winter seasons 13 of these bulls were observed close to the places of marking for several years. Two of them left the study area after some years. One, marked at the age of 1 year (bull No 12), ceased to be observable in its 5th year, and then, after 11 years, was found in the northern part of the population's area (compartment No 280). Another bull, No1, vanished when 8 yrs old, after 4 yrs of observation. Seven individuals left for more distant feeding sites (to comp. Nos 391, 334 and 251). The remaining 7 males were observed near the place of marking only during the same and the following year. Then, they were seen no more, apparently indicating that they had left the study area. Those 


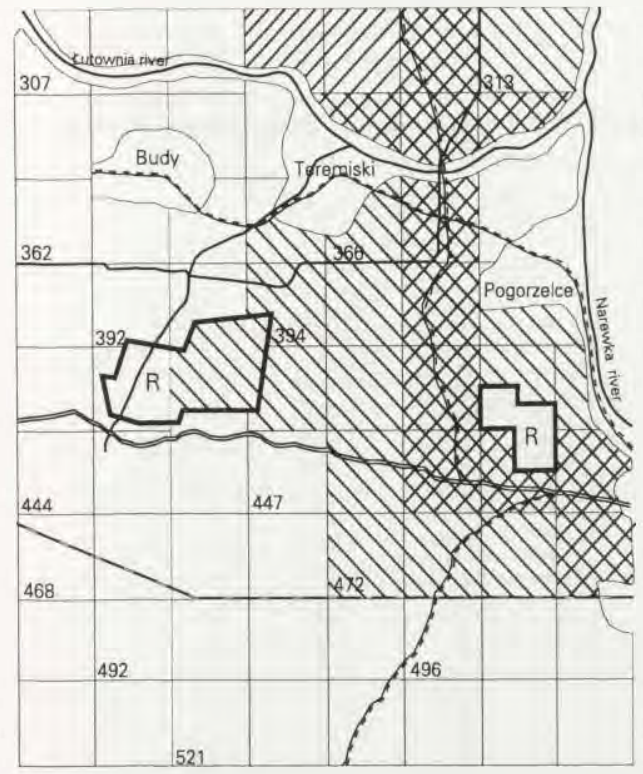

$0 \quad 12 \mathrm{~km}$

N-home range of dominant bull No 16 attending the mixed groups during rut (September 1987, range 2886 ha)

17 -home range of non dominant bull No 16 not attending the mixed groups during rut (September 1988, range 1332 ha)

Fig. 8. Monthly home range of bull 16 during rut 1987 and 1988. For explanation see Figs 1 and 6.

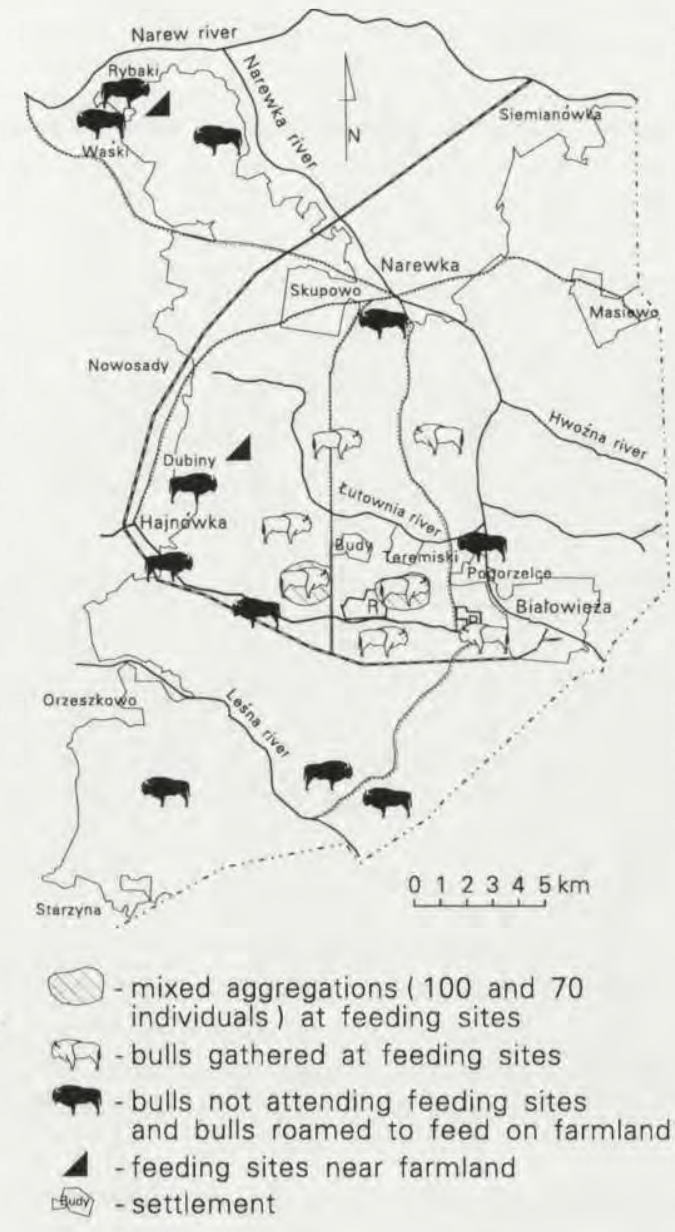

Fig. 9. Spatial distribution of bulls during winter $1987 / 88$.

leaving the study area were aged 5 or 6 and subsequently (4-6 yrs later) were seen on the forest peripheries, near farming fields. No one can exclude their participation in rut of the northern part of the population. However, during winter they were not found at supplementary feeding sites.

Mean winter home range ( $n=87$ established acreages) was $426.1 \pm 307$ ha (range 111-1443 ha) (Table 3 ). Bulls' age and home range size was significantly correlated $\left(r=0.31,0.01<p<0.001, R^{2}=9.536 \%\right)$, suggesting that younger bulls have smaller territories. During mild winters the mean home range size of a bull is larger than during severe winters but the difference is not significant statistically (Table 3 ). Bulls which remained in mixed aggregations had home range size of $224.8 \pm 162$ ha. Bulls that were either solitary or remained in bull only 
Table 3. Mean (and SD) winter home range size of marked bulls in the period 1976/77-1989/90. I - bulls appearing in two types of winter aggregations (mixed and bulls), II - bulls observed in bulls aggregation in winter, III - bulls appearing in mixed aggregations in winter. Severe winters - average daily temperature < $-1^{\circ} \mathrm{C}$, mild winters - average daily temperature $>-1^{\circ} \mathrm{C}$.

\begin{tabular}{|c|c|c|c|c|c|c|}
\hline \multirow{2}{*}{ Winter } & \multirow{2}{*}{ Category } & \multicolumn{5}{|c|}{ Home range size (ha) } \\
\hline & & $n$ & $\bar{x}$ & $\mathrm{SD}$ & Min & Max \\
\hline \multirow{4}{*}{$\begin{array}{l}\text { Severe, snowly } \\
\qquad \begin{array}{l}n=7\end{array}\end{array}$} & I & 16 & 659.1 & 260.0 & 333 & 1221 \\
\hline & II & 9 & 407.0 & 288.4 & 111 & 888 \\
\hline & III & 25 & 230.9 & 181.0 & 111 & 666 \\
\hline & $\Sigma$ & 50 & 399.6 & 294.0 & 111 & 1221 \\
\hline \multirow{4}{*}{$\begin{array}{l}\text { Mild } \\
\qquad n=6\end{array}$} & I & 14 & 737.7 & 263.4 & 111 & 1443 \\
\hline & II & 9 & 419.3 & 297.7 & 111 & 777 \\
\hline & III & 14 & 214.1 & 126.7 & 111 & 444 \\
\hline & $\Sigma$ & 37 & 462.0 & 323.1 & 111 & 1443 \\
\hline \multirow{4}{*}{$\begin{array}{l}\text { Total } \\
\qquad n=13\end{array}$} & I & 30 & 659.6 & 260.6 & 333 & 1443 \\
\hline & II & 18 & 413.4 & 284.4 & 111 & 888 \\
\hline & III & 39 & 224.8 & 162.0 & 111 & 666 \\
\hline & $\Sigma$ & 87 & 426.1 & 307.0 & 111 & 1443 \\
\hline
\end{tabular}

group had home range size of $421.2 \pm 284.4$ ha. Bulls, that were during the same winter either in bull group or mixed aggregations, had home range size of 659.6 \pm 260.6 ha. This was significantly larger than mean home range size of two remaining groups of bulls ( $p<0.001$ and $0.002<p<0.001$, respectively) (Table 3 ).

The marked males exhibited different individual patterns of spatial activity. From among 20 bulls observed during a few years, some spent most of the winter season roaming among bull aggregations and mixed aggregations on areas where they had been marked (e.g. bulls Nos 5 and 6). Others were observed most frequently in bull groups near feeding sites in comp. 446 and 448 (e.g. bull No 25) or in comp. 251, $10 \mathrm{~km}$ away from the place of marking (e.g. No 19). Some bulls preferred mixed groups in winter seasons (e.g. Nos 20 and 29). Several males left the areas where they had been marked after a short period of time (Nos 6 and 21) or after a few years (No 12) moving towards the forest peripheries. Bulls entering farmland behaved in a different manner. For example, No 14 was caught in the fields near Hajnówka, a town, in the winter of $1987 / 88$, transported to the middle of the forest, marked and set free. Next winter it appeared on farmland again, this time near Narewka, a village. In the fall of 1990 it was found again near Narewka (Fig. 10), and there it was eliminated.

From among 31 marked males, 9 individuals (29\%) permanently or for longer periods of time entered farmland during late fall, in snow-free winters and early in the spring. Six of them (19\%) visited farming fields beyond the forest limits and three individuals (10\%) penetrated fields belonging to mid-forest villages. The 
Fig. 10. Migration routes of bull No 14 to farmland during several years.

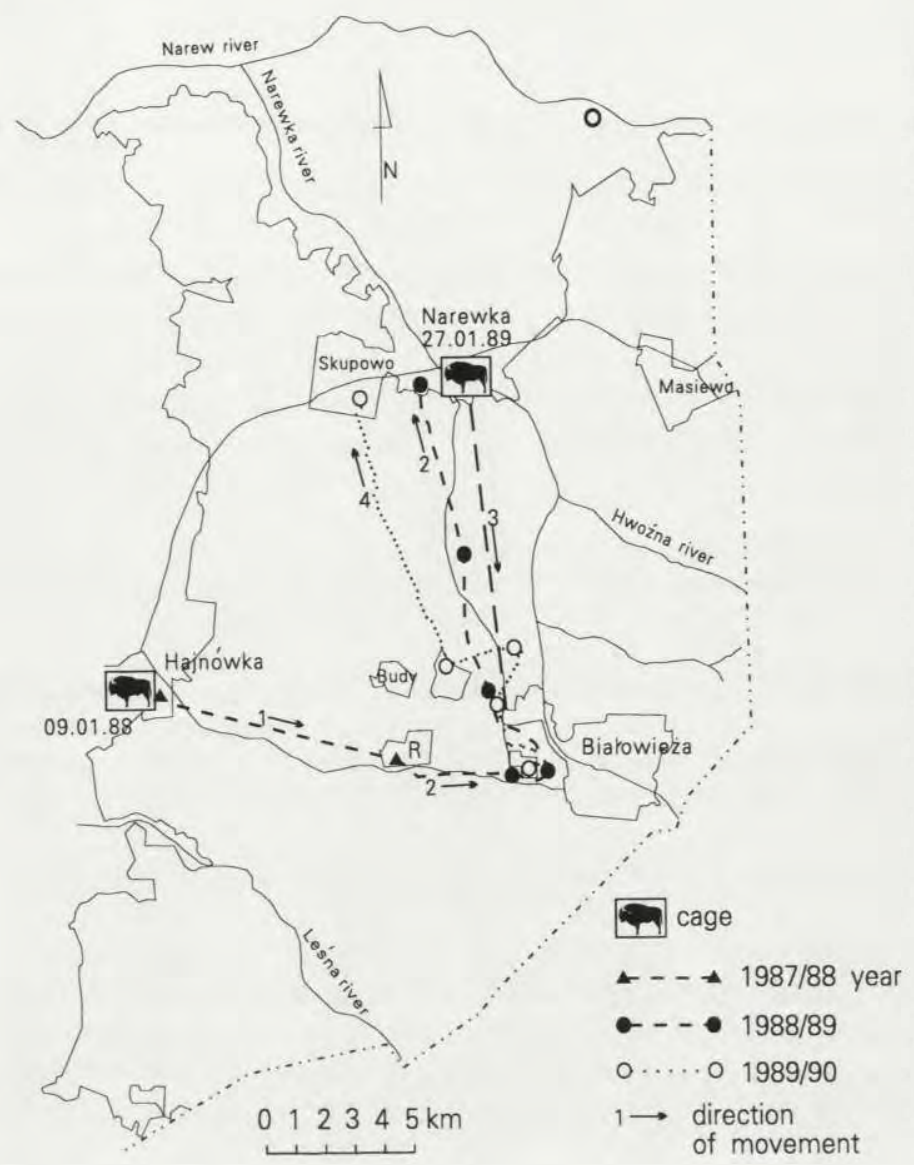

marked bulls entering farmland were over 6 years of age. From among eight animals caught on farmland beyond the forest limits, marked and transported to the forest center, all returned to the fields. On the example of bull No 14, caught three times, one can see that bulls which had left the population's home range in favor of periodical visits to farmland did not change their behavioral patterns despite of being caught and transported to the home range center. Having observed for a few years the same marked males inhabiting the home range of the population, one can say that bulls over 10 years of age start to visit farming fields located in the middle of the population's area. Some individuals do so permanently (Nos 16 and 25), others temporarily (Nos 26 and 27). For example, the 12-year-old bull No 16, remained close to the fields of Teremiski and Pogorzelce villages, from fall till spring of one season, and next fall the animal moved to the farmland of Białowieża village. Since 1990 this bull has not been observed in mixed groups in summer as it had been in previous years. Another bull, No 32, entered at the age of 12 the fields of Białowieża and fed there for the whole vegetative period. 


\section{Habitat use}

During the whole snow-free season, i.e. from mid-April through the end of October, bulls used fresh and moist deciduous forests $-48.4 \%$ of encounters (Table 4, Fig. 11). Fresh deciduous forest was used throughout the whole growing season (42.8\% of encounters). Most use was in spring (April-June) and in September (Fig. 12). Mixed coniferous forests was the second most used habitat $-28.9 \%$ of encounters. Bulls intensified their feeding in mixed coniferous forests in July, August and October (Fig. 12). Mixed deciduous forests were used during the whole growing season $-19.1 \%$ of encounters. They were used more in June and July. Alder forests

Table 4. Seasonal changes in habitat use by bulls in different forest types (1976-1990). Abbreviations: MCF - mixed coniferous forest, MDF - mixed deciduous forest, FDF - fresh deciduous forest, MoDF - moist deciduous forest, $\mathrm{Aa}$ - ash alderwoods, A - alderwood.

\begin{tabular}{|c|c|c|c|c|c|c|c|}
\hline \multirow{4}{*}{ Month } & \multirow{4}{*}{$n$} & \multicolumn{6}{|c|}{ Forest type } \\
\hline & & MCF & MDF & FDF & MoDF & $\mathrm{Aa}$ & A \\
\hline & & \multicolumn{6}{|c|}{$\%$ of study area } \\
\hline & & 38 & 9.9 & 16 & 13 & 10.2 & 4.9 \\
\hline April & 158 & 24.7 & 10.1 & 48.1 & 10.8 & 5.0 & 1.3 \\
\hline May & 289 & 24.6 & 18.3 & 47.0 & 8.0 & 1.4 & 0.7 \\
\hline June & 279 & 20.8 & 26.9 & 46.9 & 2.9 & 1.1 & 1.4 \\
\hline July & 212 & 35.4 & 23.6 & 38.2 & 1.4 & 0.9 & 0.5 \\
\hline August & 149 & 38.9 & 14.0 & 37.6 & 3.4 & 3.4 & 2.7 \\
\hline September & 127 & 24.4 & 17.3 & 44.1 & 7.1 & 4.7 & 2.4 \\
\hline October & 137 & 42.3 & 15.3 & 30.7 & 8.0 & 1.5 & 2.2 \\
\hline $\bar{x}$ & 1351 & 28.9 & 19.1 & 42.8 & 5.6 & 2.2 & 1.4 \\
\hline
\end{tabular}

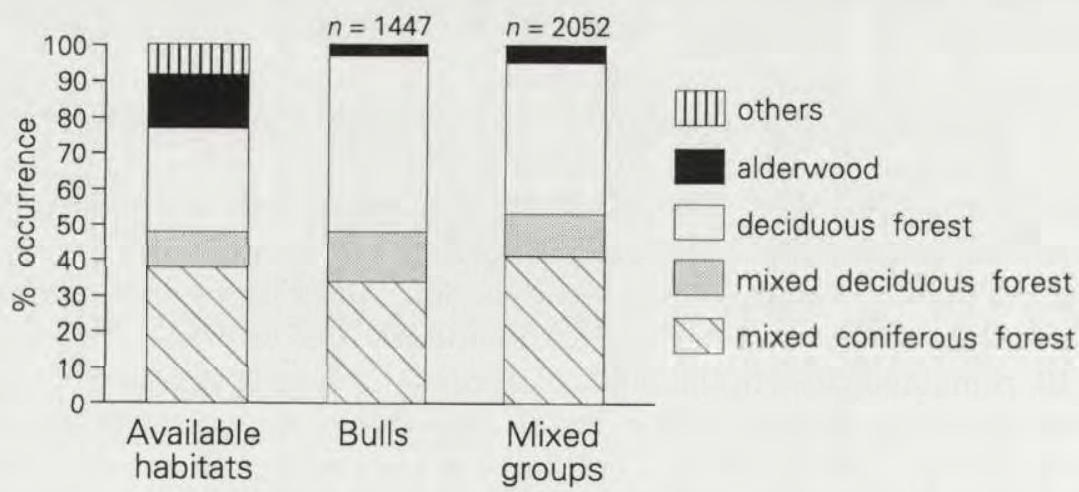

Fig. 11. Available habitat (\%) and percent frequency of occurrence of observations of European bison in habitats during snow-free season. 


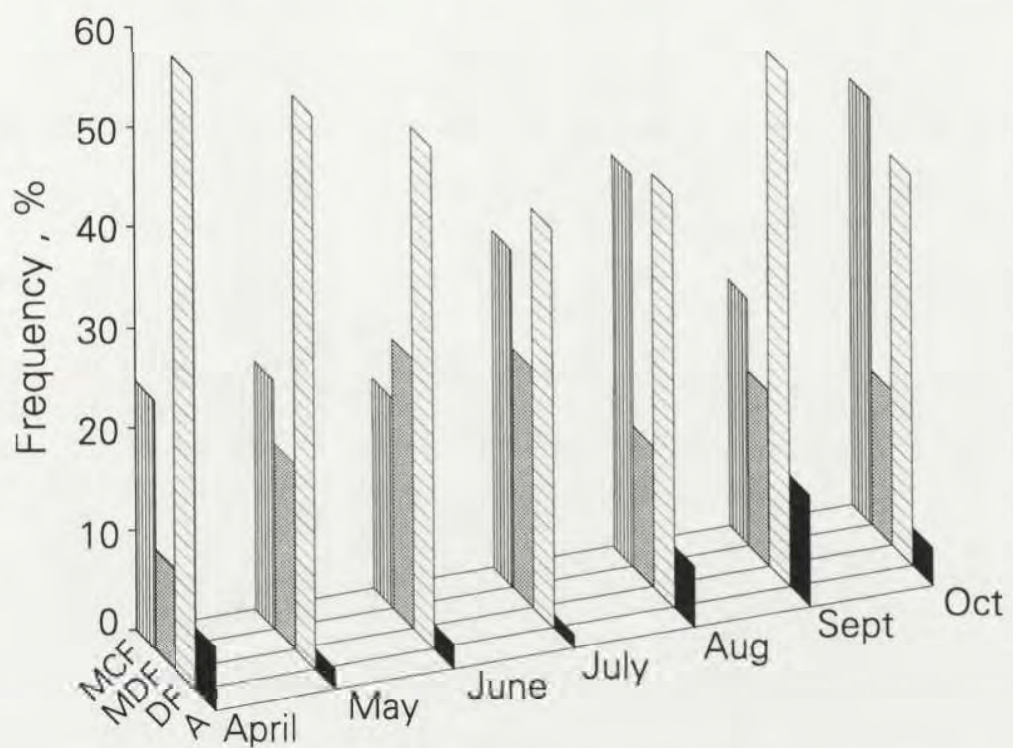

Fig. 12. Seasonal changes in habitat use of bulls during snow-free period. See Table 4 for more explanations.

Table 5. Frequency of observation (\%) of bull in different forest types of the Białowieża Primeval Forest in 1976-1990, $n$-number of observtions. For explanation of forest type see Table 4

\begin{tabular}{|c|c|c|c|c|c|c|c|}
\hline \multirow{2}{*}{ Year } & \multirow{2}{*}{$n$} & \multicolumn{6}{|c|}{ Forest type } \\
\hline & & $\mathrm{MCF}$ & MDF & FDF & MoDF & $\mathrm{Aa}$ & A \\
\hline 1977 & 53 & 45.2 & 13.2 & 30.2 & 5.7 & 3.8 & 1.9 \\
\hline 1978 & 69 & 59.4 & 13.0 & 21.7 & 5.9 & - & - \\
\hline 1979 & 53 & 22.6 & 20.8 & 49.0 & 3.8 & 1.9 & 1.9 \\
\hline 1980 & 94 & 39.4 & 9.6 & 37.2 & 11.7 & 2.1 & - \\
\hline 1981 & 130 & 31.5 & 10.8 & 46.9 & 5.4 & 4.6 & 0.8 \\
\hline 1982 & 90 & 26.6 & 20.0 & 38.9 & 5.6 & 6.7 & 2.2 \\
\hline 1983 & 127 & 26.0 & 32.2 & 30.0 & 7.1 & 1.6 & 3.1 \\
\hline 1984 & 92 & 21.8 & 16.3 & 44.5 & 8.7 & 6.5 & 2.2 \\
\hline 1985 & 100 & 22.0 & 7.0 & 65.0 & 6.0 & - & - \\
\hline 1986 & 49 & 26.5 & 16.3 & 53.1 & 4.1 & - & - \\
\hline 1987 & 170 & 24.1 & 15.9 & 50.6 & 5.9 & 2.3 & 1.2 \\
\hline 1988 & 148 & 19.6 & 25.0 & 51.3 & 2.7 & 0.7 & 0.7 \\
\hline 1989 & 139 & 25.9 & 38.1 & 33.0 & 1.5 & - & 1.5 \\
\hline $\bar{x}$ & 1351 & 28.9 & 19.1 & 42.8 & 5.6 & 2.2 & 1.4 \\
\hline
\end{tabular}

were utilized to a small degree $-3.6 \%$ of encounters (Table 4 ). There were some differences in the habitat use yearly as well as seasonal variation (Table 5). 


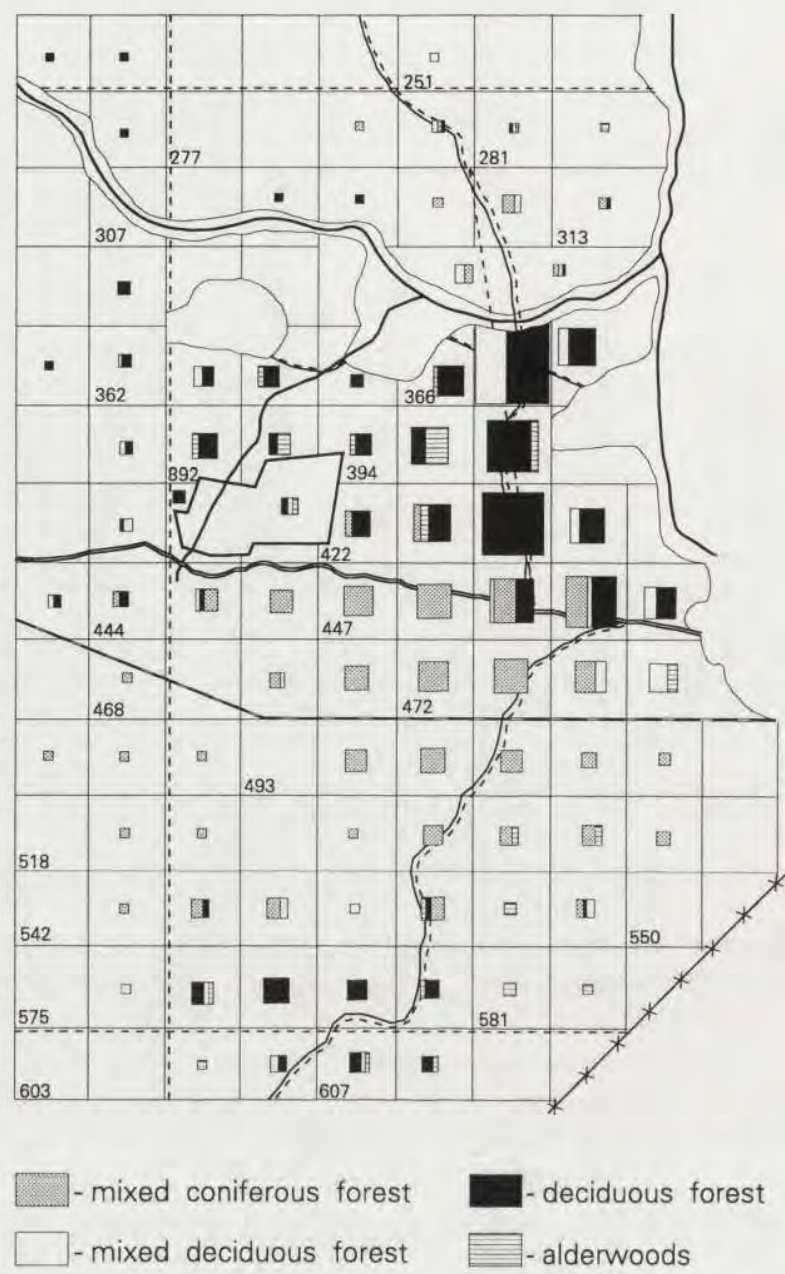

Fig. 13. Frequency of observations of bulls in forest compartments of the Białowieża forest in snow-free period ( $n=1447$ obs.). The size of squares are proportional to the number of observations of bulls in given forest type and compartment. For explanation see Fig. 1.

During the growing season the study area is not penetrated by the bulls equally. Compartment No 367 was the most often visited forest compartment, the following ones were: $450,449,424$, and 396 - Fig. 14. The two most liked compartments are mosaics of various kinds of forests containing fragments of a mixed deciduous forest, the most prefered habitat here (Fig. 13). The remaining parts of the Białowieża Primeval Forest preferred by bulls are fresh deciduous and mixed coniferous forests in at least $50 \%$ of the acreage.

In the growing season bulls are feeding both at the forest floor and in a so-called open area. Over the growing season bulls were encountered in open areas (37\% of observations) and feeding at forest floor $(63 \%)$; in the latter case the forest was 


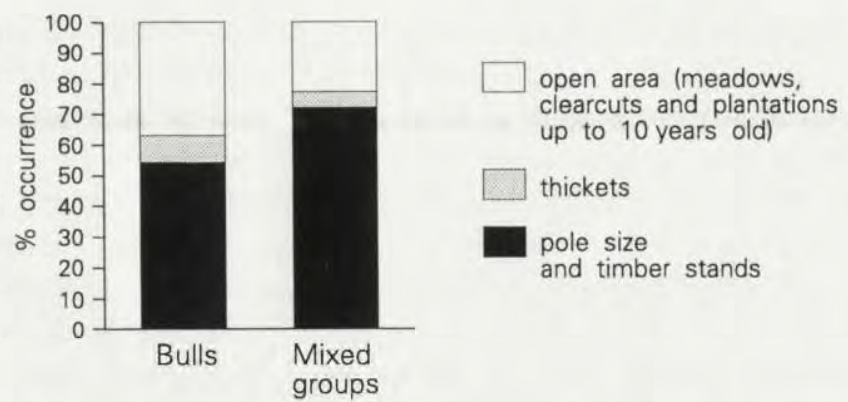

Fig. 14. Frequency of observations (\%) of bison in tree stand of different age classes during snow-free period.

most often over 20 yrs old ( $54 \%$ of encounters). Thickets of $10-20$ years of age were visited rarely ( $9 \%$; Fig. 14).

The way of utilizing the habitat by bulls is similar to that of mixed groups. Feeding bulls make loops and return to the places after a few days (Figs 6 and 7). However, their monthly route over an area consists of loops overlapping so densely that in some instances this route may be visualized only within ten days (Fig. 6).

In winter bulls utilize natural food resources to a small degree. They feed themselves with hay at the supplementary feeding sites or at feeding racks set up by hunters. Some of them use the green vegetation of the farming fields (winter crop). Barking of trees (aspen, oak, hornbeam and linden) intensifies towards the end of winter.

\section{Discussion}

Since very little data are available on the size and composition of herds, movement pattern and habitat use by European bison bulls in free-ranging populations we compared these data with those of the American bison Bison bison.

Social relations of bulls

One can still regularly observe small groups, of 1-3 males, in the snow-free season ( $91 \%$ of observations, Krasiński 1978 , and $94 \%$, this study). Since the Białowieża population formed, the number of solitary bulls during the rut has risen up to $80 \%$. The majority of solitary males were $\geq 7$ yrs old $(73 \%$ of observations). Previously, it was believed that only old males become solitary (Bojanus 1827). However, as early as in 1903 Karcov noticed that middle-aged and strong bulls began to roam alone. Similarly, $77 \%$ of American bison bulls from the Wood Buffalo National Park population live solitarily; $34 \%$ of them are $\geq 7$ yrs old. From among the sub-adults, 65\% are solitary (Fuller 1960). In the Wind Cave National Park solitary males were encountered in $58.6 \%$ of observations (Shult 1972). In the wood bison population inhabiting the Mackenzie Bison 
Sanctuary it was found that with increasing age males were often solitary (Komers et al. 1992). During the rut there were more solitary bulls than males roaming in herds in wood bison (Melton et al. 1989), again similar to what we found with European bison. In the population of prairie and wood bison hybrids of the Slave River Lowlands, the size of bull groups decreases during the rut (Calef and Camp 1987). We believe that the increased number of solitary bulls observed during the rut results from an intensified penetration of the area by single males participating in reproduction and seeking cows at rut. Although recent data from wood bison suggest that "males leave female groups in order to recover, not for the purpose of the searching for new female groups" (Komers et al. 1992). European bison, characterized by a less intense group fluidity during the rut than wood bison may need to do more searching for mates than wood bison.

Observations of marked animals confirm earlier suggestions by Krasiński (1978) about the relationship between a male group size and age. Young male form larger groups than older bulls. The bull herds, like mixed ones (Krasińska et al. 1987), are not based on family relationships, and are not stable. The composition and size of bull groups, like that of mixed herds, change. Changes in composition of bull groups may result form the fact that home ranges are not defended and frequently overlap. Exchange of males is not a violent process. In the rut bull herds are observed rarely, and if so, they display no signs of aggressive behavior. This is contrary to what is observed between adult bulls in mixed groups during the rut. The reason of changing composition during pre-rut period may be an encounter with a mixed group joined for a short period of time by the strongest male from the bull herd. The remaining males roam to other places.

We found no stable domination in reproduction of male European bison. Nevertheless, Lott (1979) believes that bulls preserve their reproductive potentials till death. He did not find that a high social status of a bull was related to its age or body weight. Only many years observations of marked bulls of a known age may univocally solve this question for European bison. In free living European bison population the age and condition males have a considerable influence on its domination in reproduction. Bulls joining mixed groups during the rut do not disturb the existing hierarchical structures. Only in relation to younger bulls do the new-comers occupy higher social ranks in a group (Cabon-Raczyńska et al. 1987).

Observations of marked bulls' share in reproduction confirm earlier conclusions by Krasiński (1978); despite the fact that bulls become sexually mature early, they do not participate in reproduction before 6 yrs of age. The time of a bull's sexual activity is short; its upper limit reaches 11-12 yrs of age. This limitation results from behavioral factors since captive bulls perform reproductive functions even till the age of 20 (Krasiński and Raczyński 1967, Caboń-Raczyńska et al. 1987, Krasińska and Krasiński 1991).

The tendency of reproductive bulls to become solitary during periods other than the rut has been observed since the beginning of this population (Krasinski 1983). 
American bison bulls also enter reproduction late, i.e. at the age of 5-6 (Egerton 1962, Lott 1981). Their groups are slightly coherent (Meagher 1973). The integration of bull herds is markedly lesser than that of cows (Shult 1972). Domination among mature bulls is looser and more temporary than among members of mixed groups (Lott 1979). In the Mackenzie Bison Sanctuary males of wood bison aged 6-12 dominate in reproduction (Komers et al. 1992).

In the Białowieża Primeval Forest bulls began to form separate aggregations in winter 1963/64, when the population was 70 animals. Krasiński (1978) found that $50-90 \%$ of bulls roamed in winter bull herds in different years during the early 1970 's. The remaining males stayed in mixed groups. Our investigations confirm this in following years. However, the winter bull aggregations gathering around feeding sites recently are smaller, containing up to 9 animals. Previously they numbered up to 15 bulls. Larger male aggregations are currently found on farmland, yet they do not exceed 12 individuals.

Mixed groups and bull herds are basic structural units within the populations of both representatives of the genus Bison. Herds of European bison bulls are small and less stable, and display looser relations than mixed groups. Mixed groups of wood bison Bison bison athabascae are extremely fluid, more so than some male groups. Some of the males also tend to live as solitary. Young, sexually immature bulls abstain from reproduction until full physical development at the age of $5-6$.

\section{Spatial distribution}

In the Białowieża Forest, in the snow-free season which parallels the growing season, bison fully utilize the food resources of the forest. Home range size of individuals within mixed and bull groups and of solitary males likely depend on the seasonally changing food abundance of particular habitats, the spatial distribution of preferred habitats and on social relationships. Solitary bulls and bull groups in snow-free periods cover about half of the territory mixed groups do, which is 23 and $47 \mathrm{~km}^{2}$ respectively. Home ranges of adult wood bison males are significantly smaller than that of females of this species (Larter 1988, Larter and Gates 1990). Food and social class are important factors in determining of home ranges size of wood bison (Larter and Gates 1994). In comparison with wood bison (Larter 1988, Larter and Gates 1990) whose annual home ranges of bulls equals $433 \mathrm{~km}^{2}$, males of the European bison occupy a visibly smaller home range $\left(23 \mathrm{~km}^{2}\right.$ in the snow-free periods). The reason for this may be differences in the methods of estimating the of home ranges size, existing habitat differences (amount of suitable habitat) as well as need for seasonal migration for food. On the other hand, the data about the European bison concern only the snow-free season. The size of summer home ranges of European bison should be treated as an approximate value since the animals were not localized every day in the given season. Only radiotracking studies will allow for more precise estimates. 
In winter European bison bulls use much larger area within the Białowieża Primeval Forest than mixed herds, and they do not stay exclusively near feeding sites. Possibly one can assume that supplementary feeding in winter has less influence on their natural movement during winter than mixed groups.

Observations of marked males indicate that some bulls at 5-6 yrs, tend to move towards the peripheries of the population's area. We can suppose that some of bulls which reach maturity seek new territories to live at in order to facilitate the reproductive success. Similarly, mature males of the American bison are observed on the peripheries of the population's area (Gates and Larter 1990, Shaw and Carter 1990). Shaw and Carter (l.c.) are of the opinion that older male bison are more inclined to search new territories than young ones, and that they repeat such behavior over several following years. Nomadism of males in both the European and American bison seems to be an innate feature in agreement with Howard's definition (cited after Gates and Larter 1990). Repetitive entering of fields by the same marked bulls permits the assumption that feeding on farmland may be fixed. Whether these bulls remain in close touch with the population (or preferable) is not known. Only telemetric monitoring of bulls movements may confirm this assumption. Some bulls may stay at the peripheries because of illness or disease.

During normal winters the height of snow cover in the Białowieża Primeval Forest reaches $30 \mathrm{~cm}$ on an average (maximal $92 \mathrm{~cm}$ ). If the cover remains for longer, the males, like other bison, feed mainly on hay and are not mobile. During winters with little or no snow, bison take advantage of the supplementary feeding to a small degree, and disperse over a significantly larger territory than during severe winters. They approach the sites with hay once or twice a day but do not stay close to them for the whole day and night. They feed on the dry herb layer and acorns. Therefore, it appears that the fairly persistent snow cover is a factor which considerably limits the bisons' roaming in the Białowieża Primeval Forest. This limitation is stronger than it is observed in other hoofed animals inhabiting this territory. It is believed that snow depth restricts the American bison movements more than of moose in particular (Van Camp 1975, Reynolds and Peden 1987).

\section{Habitat use}

Food preference is the major factor causing concentration of bison in particular regions. Recently, a limited number of feeding clearings and large scythed meadows have been created in the Białowieża Primeval Forest. The study area includes a considerable share of mixed coniferous forests $(38 \%)$. This is why this habitat is often used seasonally by mixed bison groups. During the whole snow-free period bulls use deciduous forests (Fig. 11). Bulls also feed in open areas more frequently than mixed herds (Fig. 14). The small size of bull groups may enable them to find a sufficient amount of food on small open areas, such as: roadside rows and small mid-forest clearings. Solitary American bison males were also 
often seen feeding on clearings along roads (Fisher 1967). Wood bison in small groups or solitary use small habitat patches, likely too small for mixed groups (Larter 1988).

Bulls, like mixed herds, display seasonal changes in habitat use. Fresh deciduous forests are used mostly in early spring, which may be related to the fact that in the Białowieża Primeval Forest in this part of the forest is observed the earliest development of the herb layer (Falińska 1973). Use of mixed coniferous forests by bulls increases in July and August. For mixed groups this happens in June and July. Fresh and moist deciduous forests are used by bulls throughout the whole growing season. Differences in habitat use between bulls and mixed groups may result from the fact that the observations were not carried out in the same years. In 1977-1982, when the mixed herds and bulls were monitored simultaneously, analogical changes in seasonal habitat use were observed. Bulls, like members of the mixed groups, can complement their diet in mixed coniferous forest when the herb layer was poor in deciduous forest. During droughts bulls do not visit mixed coniferous forests for long periods of time but feed mainly in deciduous or even on alder woods habitats.

Apart from the rut, the major incentive to movements for bulls, cows and young animals is the search for food (Cabon-Raczyńska et al. 1987, Krasińska et al. 1987). The manner of food collection is independent from sex. All bison feed moving towards new spots making loops (Figs 6 and 7). Since a solitary bull or a small bull herd eat significantly less food than a more numerous mixed group, the former can feed on a small territory, i.e. of the size of one forest compartment (111 ha), even for 2 weeks. For wood bison, bulls move less than cows, except during the rut (Larter 1988).

Bulls often use fragments of forests which are mosaics of habitats. This may be related to their living alone or in small groups which enables to move over a small territory, and feed in several habitats within one compartment. Mixed groups, on the contrary, prefer spots where one kind of habitat predominates and occupies at least $50 \%$ of the area (Krasińska et al. 1987). Group size would appear to be a factor limiting such a strategy of habitat use.

During the rut, European bison bulls focus in the area occupied by mixed herds and are very mobile. Like males of the wood bison, they select areas of the highest density of females (Larter 1988, Komers et al. 1992).

In the summary, it appears that European bison, moving and feeding in bull and mixed groups use the environment in such a manner which reflects the size and structure of the groups, the preferences of forest habitats and the necessity to allow the regeneration of the herb layer. The basic diet comes from fresh, moist and mixed deciduous forests, and is seasonally complemented in mixed coniferous forests. Taking into consideration the differences resulting from living in various habitats, it can be said that both the European and American bison (especially the wood bison) display many similarities in the social and spatial structures as well as in the feeding strategy. 
Acknowledgements: The authors wish to express acknowledgements for the assistance in carrying on observations to Dr K. Caboń-Raczyńska, J. Dackiewicz, K. Jurgiel, as well as to M. Szlachciuk and M. Szuma. We also thank M. Szlacheiuk and K. Zub for drawing illustrations. Many thanks are due to Prof $Z$. Pucek for his general suggestion and critical reading of the earlier drafts of this paper, and to Dr N. C. Larter from Department of Zoology, University of British Columbia for critical reading and valuable comments on this paper, and for correcting the English.

\section{References}

Bojanus H. L. 1827. De Uro nostrate eiusque sceleto commentatio. Nova Acta physica-medica Academiae Caesareae Leopoldine Carolinae Naturae Curiosorum, Bonnae 23: 413-478.

Caboń-Raczyńska K., Krasińska M. and Krasiński Z. 1983. Behaviour and daily activity rhythm of European bison in winter. Acta Theriologica 28: 273-299.

Caboń-Raczyńska K., Krasińska M., Krasiński Z. A. and Wójcik J. M. 1987. Rhythm of daily activity and behavior of European bison in the Białowieża Forest in the period without snow cover. Acta Theriologica 32: 335-372.

Calef G. W. and Van Camp. J.1987. Seasonal distribution, group size and structure, and movements of bison herds. [In: Bison ecology in relation to agricultural development in the Slave River lowlands. H. W. Reynolds and A. W. L. Hawley, eds]. Occasional Paper of Canadian Wildlife Service 63: 15-20.

Egerton P. J. M. 1962. The cow-calf relationship and rutting behavior in the American bison. M. Sc. thesis, University of Alberta, Department of Zoology, Edmonton: 1-155.

Falińska K. 1973. Seasonal dynamics of herb layer in forest communities of Białowieża National Park. Phytocenosis 2: 1-120.

Fischer A. W. 1967. Observations on behavior of lone bull bison. Procedings of Iowa Academy of Science 74: 87-91.

Fuller W. A. 1960. Behavior and social organization of the wild bison of Wood Buffalo National Park, Canada. Arctic 13: 1-19.

Gates C. C. and Larter N. C. 1990. Growth and dispersal of an eruping large herbivore population in Northern Canada: The Mackenzie wood bison (Bison bison athabascae). Arctic 43: 231-238.

Karcov G. 1903: Belovezhskaja Pushcha. Artist. Zaved. AF Marksa. S-Petersburg: 1-414.

Komers P. E., Messier F. and Gates C. C.1992. Search or relax: the case of bachelor wood bison. Behavioral Ecology and Sociobiology 31: 195-203.

Krasińska M., Caboń-Raczyńska K. and Krasiński Z. A. 1987. Strategy of habitat utilization by European bison. Acta Theriologica 32: 147-202.

Krasińska M. and Krasiński Z. A. 1991. Strategie der Benutzung des Habitats von Bullen der Wisente im Urwald von Białowieża. Seevögel 12: 63-66.

Krasiński Z. 1967. Free living European bison. Acta Theriologica 12: 391-405.

Krasiński Z. A. 1978. Dynamics and structure of the European bison population in the Bialowieża Primeval Forest. Acta Theriologica 23: 13-48.

Krasiński Z. A. 1983. The first 10 years of free breeding of bison in the Białowieża Primeval Forest 1952-1961. Parki Narodowe i Rezerwaty Przyrody 4: 39-50. [Polish with English summary]

Krasiński Z. A., Caboń-Raczyńska K. and Krasińska M. 1982. Immobilization and marking of the European bison. Acta Theriologica 27: 181-190.

Krasiński Z. and Raczyński J. 1967. The reproduction biology of European bison living in reserves and in freedom. Acta Theriologica 12: 407-444.

Larter N. C. 1988. Diet and habitat selection on erupting wood bison population. M. Sc. thesis, University of British Columbia, Vancouver: 1-109.

Larter N. C. and Gates C. C. 1990. Home ranges of wood bison in an expanding population. Journal of Mammalogy 71: 604-607. 
Larter N. C. and Gates C. C. 1994. Home-range size of wood bison: effects of age, sex and forage availability. Journal of Mammalogy 75: 142-149.

Lott D. F. 1979. Dominance relations and breeding rate in mature male American bison. Zeitschrift für Tierpsychologie 49: 418-432.

Lott D. F. 1981. Sexual behavior and intersexual strategies in American bison. Zeitschrift für Tierpsychologie 56: 97-114.

Meagher M. M. 1973. The bison of Yellowstone National Park. National Park Service Scientific, Monographs Series 1: 1-161.

Melton D. A., Larter N. C., Gates C. C. and Virgl J. A. 1989. The influence of rut and environmental factors on the behavior of wood bison. Acta Theriologica 34: 179-193.

Reynolds H. W. and Peden D. G. 1987. Vegetation, bison diets and snow cover. [In: Bison ecology inrelation to agricultural development in the Slave River lowlands. H. W. Reynolds and A. W. L. Hawley, eds]. Occasional Paper of Canadian Wildlife Service 63: 39-45.

Shaw J. H. and Carter T. S. 1990. Bison movements in relation to fire and seasonality. Wildlife Society Bulletin 18: 426-430.

Shult M. J. 1972. American bison behavior patterns at Wind Cave National Park. Ph. D. thesis, Iowa State University, Ames: 1-178.

Van Camp J. 1975. Snow condition and the winter feeding behaviour of Bison bison in Elk Island National Park. Canadian Wildlife Service: 53-75.

Received 28 October 1993, revised 24 November 1994, accepted 15 December 1994. 